\title{
Determination of Tolterodine Tartrate in Bulk and Formulation by Extractive Colorimetric Method using Tropaeolin 000-1
}

\author{
Mani Ganesh ${ }^{1}$, Pushparaj Hemalatha1, Mei Mei Peng1, Rajangam Vinodh, \\ Kalaimani Saktimanigandan ${ }^{2}$ and Hyun Tae Jang ${ }^{1 *}$ \\ ${ }^{1}$ Department of Chemical Engineering, Hanseo University, 360 Daegok-ri, Haemi-myun, Season -356-706, Chungcheongnam- \\ do, South Korea, ${ }^{2}$ Alkem Lab Ltd, C-17/7, MIDC Industrial Area, Taloja-410208, Raigad District, Navi Mumbai, Maharashtra, \\ India
}

*For correspondence: Email: htjang@hanseo.ac.kr; Tel: +82-41-660-1423

\begin{abstract}
Purpose: To develop a new simple, accurate, precise and fully validated extractive colorimetric method for the determination of tolterodine tartrate (TL) in bulk and in tablet dosage form,

Method: A chloroform extractable orange red complex formed between the acid dye, tropaeolin OOO-1 and tolterodine in acid media is the basis for this method. The maximum wavelength of absorbance of the complex was $503 \mathrm{~nm}$. The validation parameters such as stability, accuracy, precision, robustness and ruggedness were evaluated according to International conference on harmonization (ICH) and United States Pharmacopoeia (USP) guidelines.

Results: The absorbance of the complex obeyed Beer law over the range $1-30 \mu \mathrm{g} / \mathrm{mL}$ with a correlation coefficient of 0.9945 , with a molar absorptivity and Sandal's sensitivity of 0.0398 and 1.1954 $x 10^{4}$, respectively. The lower limit of detection (LOD) and of quantification (LOQ) of the method were 0.08 and $1 \mu \mathrm{g} \mathrm{mL}^{-1}$, respectively.

Conclusion: The developed method is validated and has high recovery and precision, and thus is suitable for routine analysis of the drug in bulk and formulations.
\end{abstract}

Keywords: Tolterodine, Tropaeolin, Extractive colorimetry, Validation, Solid dosage

Tropical Journal of Pharmaceutical Research is indexed by Science Citation Index (SciSearch), Scopus, International Pharmaceutical Abstract, Chemical Abstracts, Embase, Index Copernicus, EBSCO, African Index Medicus, JournalSeek, Journal Citation Reports/Science Edition, Directory of Open Access Journals (DOAJ), African Journal Online, Bioline International, Open-J-Gate and Pharmacy Abstracts

\section{INTRODUCTION}

The antimuscarinic drug, tolterodine tartarate $(\mathrm{TL})$, is chemically (R)-N,N-diisopropyl-3-(2hydroxy-5- methylphenyl)-3-phenylpropanamine L-hydrogen tartarate, and is used to treat urinary incontinence [1]. It is the drug of choice for the treatment of urinary incontinence, which has a high potency to selectively bind with the cholinergic muscarinic receptors that mediates contraction there by in controls the hyperactive the urinary bladder and prevent the frequent urinations [2-4].

The methods reported in the literature for its determination either in biological matrix or in pharmaceutical formulations are ultra violet (UV) and visible spectrophotometric methods [5-9], High Performeance Liquid Chromatography (HPLC) [10,14], Ultra High performance liquid chromatography (UPLC) [14] and potentiometric determinations using ion selective electrodes [15]. Even though, the regular methods such as 
HPLC and liquid chromatography- electron spray tandem mass spectrophotmetry (LC-MS/MS) are more accurate in estimating the drug in nanogram level but they need complex sample treatment, expensive solvents and instruments, and reagents for analysis. Though, the UV methods are simpler to consider for estimating drug its sensitivity is poor because of UV absorbing solvents or the excipients used in formulations. Among the colorimetric methods of estimation, the extractive colorimetric methods use simple reagent and non hazardous reaction conditions this makes them very easy to handle for the routine analysis of the target. In extractive colorimetric methods, the dyes commonly used are methyl orange (MO), bromocresol green (BCG), phenol red (PR), tropaeolineo-oo (TP) [16-18].

From literature survey we found that none of the methods has been reported for the determination TL using tropaeolineo-oo1 (TO) as an ion pairing reagent. Hence, in this study we aimed to develop an extractive colorimetric procedure using tropaeolineo-001 (TO) The main aim of the present report was to establish a simple, accurate, precise and validated extractive colorimetric method for the determination of tolterodine.

\section{EXPERIMENTAL}

\section{Chemicals}

Standard tolterodine tartarate was obtained from Sigma Aldrich, Germany and tropaeolineo-oo1 (TP) was procured form TCl chemicals, Korea. All other chemicals of analytical reagent grade were purchased from Daejung Chemicals \& Metals, Gyeonggi-do, South Korea. Double distilled water was used to prepare all solutions. Freshly prepared solutions were used for method development and validation. Tablets containing 4 $\mathrm{mg}$ TL were purchased from a retail pharmacy.

\section{Instrumentation}

A Shimadzu UV mini-1240 UV-Visible spectrophotometer was used for all spectral measurements with Shimadzu UV Probe system software (version 2.1) and SCINCO, Neosys2000 DRS-UV provided with liquid sample handling accessories.

\section{Preparation of stock solution of TL}

A stock solution of $1 \mathrm{mg} \mathrm{mL}^{-1}$ was prepared by dissolving an accurate quantity of $T L$ in water and then the final volume was made up to the mark with water. Working standards were prepared by suitably diluting the above standard stock solution.

\section{Sample preparation}

From the $100 \mu \mathrm{g} \mathrm{mL}^{-1}$ working standard solution, aliquots were transferred in to a series of $100 \mathrm{~mL}$ separating funnels then add $2 \mathrm{~mL}$ aqueous solution of $0.2 \% \mathrm{w} / \mathrm{v}$ TO reagent shaken well then add $6 \mathrm{~mL}$ of $0.1 \mathrm{M} \mathrm{HCl}$ mixed well for complete reaction. To extract the complex thus formed $10 \mathrm{~mL}$ of chloroform was added, shaken well and kept aside for few minutes to aid complete separation of two layers. To remove the water in the organic layer it was passed through anhydrous sodium sulphate (previously dried) in a funnel plugged with cotton wool.

\section{$\lambda$-max and linearity determination}

Full scan absorption spectrum of the orange red TL-TO ion-pair complex was obtained by scanning the chloroform layer of the chromogen from $400-800 \mathrm{~nm}$ against a reagent blank prepared by the same procedure by omitting the drug. To determine Beer's law limit, a calibration curve was constructed by plotting absorbance against concentrations from 1-30 $\mathrm{gg} \mathrm{mL}^{-1}$

\section{Method validation}

For the method optimization was carried out to determine the rapid and quantitative formation of complexes by a number of preliminary experiments. USP [19] and $\mathrm{ICH}$ [20] guidelines were followed for method validation. From the trials, $0.1 \mathrm{M} \mathrm{HCl}$ was found to be suitable to form the complex by the liberation of free dye and drug from their salts this makes them to form ion pair here the use of buffer was avoided because the acid buffers may contains the $\mathrm{Na}^{+}$or $\mathrm{K}^{+}$ion which may cause the decrease the dissociation of dye form its salts. Chloroform was chosen as better choice of solvent for extraction among carbon tetrachloride, dichloromethane and diethyl ether. A volume of $2 \mathrm{~mL}$ of TO $(0.2 \% \mathrm{w} / \mathrm{v})$ was found to be optimum to complete the complexation this was discussed in the latter section on effect of $\mathrm{MO}$ concentration.

\section{LOD and LOQ}

The limit of detection (LOD) is the lowest possible amount of drug that is detectable by the method, LOD was determined by using the following formula LOD $=\kappa \sigma a / b$ where constant $\mathrm{K}=3$, ' $\sigma$ ' is the standard deviation with intercept (a) and slope (b). The limit of quantitation (LOQ) is the lowest possible amount of the drug that is 
possible to estimate by the proposed method this can be established using following formula: $\mathrm{LOQ}=\mathrm{k} \sigma \mathrm{a} / \mathrm{b}$, where $\mathrm{k}=10 \sigma$ is the standard deviation with intercept (a) and slope (b).

\section{Method precision}

The precision of an analytical procedure expresses the closeness of agreement between a series of measurements obtained from multiple sampling of the homogeneous sample under the prescribed conditions. This can be expressed in two terms first one is intra-day precision, was calculated from results obtained after a fivefold replicate analysis of sample on the same day. Second is inter-day precision, was calculated from the results obtained from the same sample which was analyzed on five consecutive days.

\section{Accuracy of the method}

Accuracy of the method is the degree of agreement between the value obtained by the method and the true value. In general this can be established by conducting recovery studies by adding a definite amount of pure drug to a preanalyzed sample and analyzes the mixed sample by the proposed procedure.

\section{Application of the method to formulations}

Twenty tablets were weighed and powdered. The average weight of each tablet was calculated. A quantity of powder required for specific dilution was accurately weighed and transferred into a volumetric flask. The contents of the flask were dissolved in water and the final volume was made up to the mark with water and filtered through a Whatman filter paper No. 40. Convenient aliquots from this solution were taken for the assay of TL.

\section{Study of interference and placebo study}

Interference studied by mixing known amount of TL $(10 \mathrm{mg})$ with specified amounts of the common excipients such as magnesium steartae, starch and talc in their recommended percentages [19]. The analysis of these mixed samples was carried out by the proposed procedure explained under sample preparation from the results the recovery values for TL was calculated. Blank placebo was also prepared for comparison and the same procedure was followed.

\section{Robustness and ruggedness}

Robustness is study of effect of deliberate changes on the analytical methods. This was studied by estimating the assay of TL in tablet by making slight changes in wavelength of estimation and dye's concentration. Ruggedness is expressed by the degree of reproducibility of the test results obtained under different regular test conditions such as inter personal variation in analysis and inter instrument variations.

\section{Stability of the chromogen}

The formed chromogen should be stable for a minimum period of time i.e form the time of extraction to time of estimation. To study the stability of chromogen, specified quantity of stock solution of TL was mixed with optimized quantity of $0.1 \mathrm{HCl}$ and $\mathrm{TO}$ and kept aside for reaction and extracted with chloroform. Absorbance of the extracted chromogen was taken at various time intervals.

\section{Statistical analysis}

All the statistical analysis such as statdard deviation, correlation co-efficiennt and 't-test' at $95 \%$ confidence level were performed using Origin Pro software version 8 (Origin lab Corporation, MA 01060, USA).

\section{RESULTS}

\section{Maximum absorbance}

Absorption spectrum of the yellow TL-MO ionpair complex was obtained by the full scanning the chloroform extracted orange red chromogen from $400-800 \mathrm{~nm}$. The results of overlay spectra of the chromogen of the sample were depicted in Fig. 1. Maximum absorbance $(\lambda$-max) was noted at $503 \mathrm{~nm}$, and this was used throughout the method development and validation.

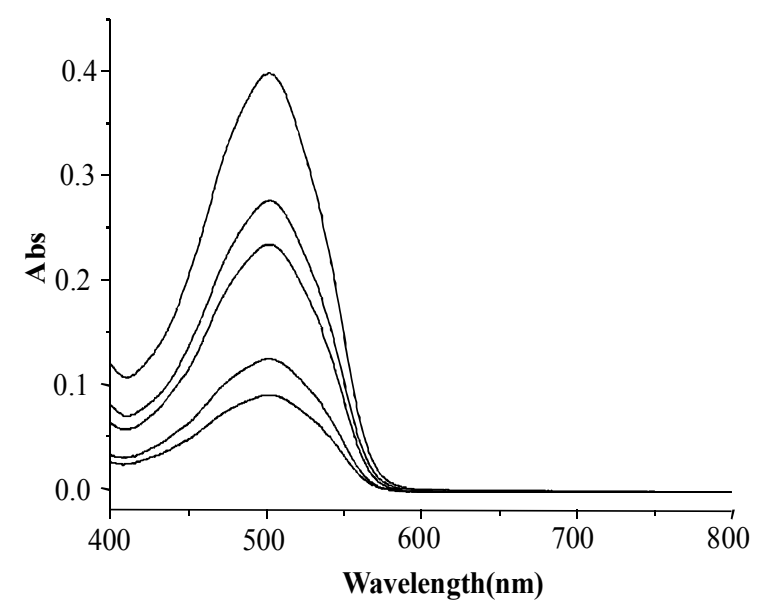

Figure 1: Full scan overlay absorption spectra of TLTO ion association complex 


\section{Validation data}

To make the method to be adoptable for routine analysis of the TL, method optimization was carried out by a number of preliminary experiments to determine quantitative formation of colored ion-pair complexes. From the trials it was noted that the formation of color required only $6 \mathrm{ml}$ of $0.1 \mathrm{M} \mathrm{HCl}$ to dissociate the drug and dye from their respective salts. In case of solvent suitability for extraction, various solvents were tested and chloroform was found to be most suitable.

\section{Linearity and range}

Beer's law standard plot was constructed by plotting the absorbance of chromogen against its concentrations $\left(\mu \mathrm{g} \mathrm{mL}^{-1}\right)$. The regression equation for the results for the method developed is as in Eq 1.

$A=0.0264 x-0.0213(r=0.0 .995)$

where $A$ is the absorbance at $503 \mathrm{~nm}, \mathrm{x}$ is the concentration of $T L$ in $\mu g \mathrm{~mL}^{-1}$ and $r$ is the correlation coefficient. Other optical characteristics are presented in Table 1.

Table 1: Spectral characteristics of the ion-pair

\begin{tabular}{ll}
\hline Parameter & Value \\
\hline$\lambda_{\max }$ & $503 \mathrm{~nm}$ \\
Beer's law limit & $1-30 \mu \mathrm{mL}^{-1}$ \\
Sandell's sensitivity & 0.0398 \\
$(\mu \mathrm{g} \mathrm{cm} / 2 / 0.001$ abs unit) & \\
Molar absorptivity $(\Theta)$ & $1.1954 \times 10^{4}$ \\
$\quad$ (lit mol cm $\left.{ }^{-1}\right)$ & \\
Regression equation & $\mathrm{A}=\mathrm{ax}+\mathrm{b}$ \\
Slope(a) & 0.0264 \\
Intercept(b) & -0.0213 \\
Standard error on slope & 0.0006 \\
Standard error on intercept & 0.0098 \\
Correlation coefficient $(\mathrm{r})$ & 0.995 \\
\hline
\end{tabular}

\section{Structure and composition of chromogen}

Cationic tertiary nitrogen of TL and anionic azo dye TO forms an orange red complex easily in acid media. The slope ratio method was used to establish drug-dye stoichiometric and it was found the TO and TL for a 1:1 association complex. The formed TL-TO act like a single unit complex, held together by an electrostatic force of attraction ions Fig. 2.

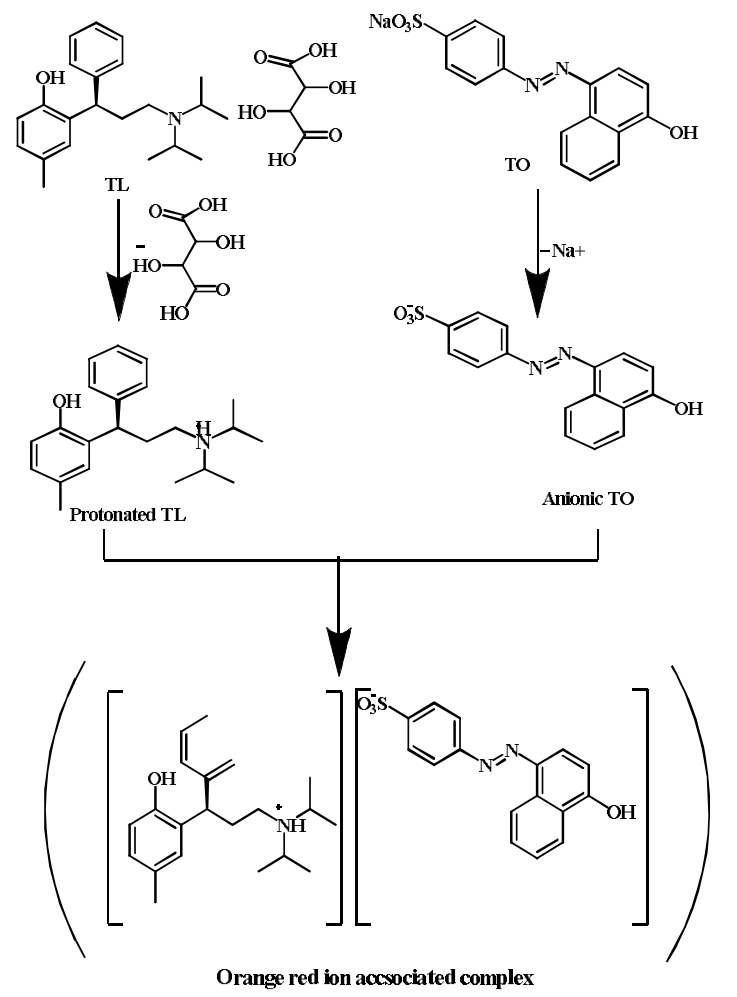

Figure 2: Structure of TL-TO complex (scheme)

\section{LOD and LOQ}

The LOD and LOQ were 0.08 and $1 \mu \mathrm{gL}^{-1}$ respectively. The low values indicate the high sensitivity of the proposed method further the values were comparable with already reported method [5].

\section{Application of the proposed method}

The mean recovery for the bulk drug was estimated to be $98.88 \pm 0.45 \%$ this proves the suitability of the method towards the estimation of bulk drug. For the application of the proposed method to formulation the marketed tablets were subjected to the analysis for the assay of TL by the proposed method and reported UV spectrophotometric method reported by Shetty and Shah [5]. From test conducted about 99.97 and $99.97 \%$ assay was resulted with the proposed and existed method (Table 2). While comparing the methods with that of reference method by statistical analysis using student t-test and F-test at $95 \%$ confidence level, they proved that results obtained by both the methods were identical and showed that there was no significant difference at $95 \%$ confidence level. 


\section{Precision of the method (repeatability)}

The results obtained for the precision of the method were presented in Table 3. The percentage relative standard deviation (\% RSD) for inter, intra-day precision was about 0.958 and 0.995 respectively which was very low and within the acceptance limits for precision experiments $(<2 \%)$, evidencing good repeatability (precision) of the method.

\section{Accuracy of the method (reproducibility)}

The recovery executed at three levels $(50,75$, and $100 \%$ to the content of the TL in tablet were resulted with $0.92-1.02 \%$ (\% RSD) for TL and the same was presented in the Table. 3 . The above \% RSD was found within the acceptance limit for accuracy of $<2 \%$ RSD this good accuracy of the purposed method.

\section{TO concentration, quantity and stability}

The effect of concentration of TO was studied measuring the absorbance of solutions containing $\mathrm{TL}\left(10 \mu \mathrm{g} \mathrm{mL} \mathrm{m}^{-1}\right)$, and $2 \mathrm{~mL}$ of TO solution at various concentration $(0.1-0.3 \%$ $w t / v)$. The results are portrayed in Fig. 3(a). As TO concentration of $0.2 \% \mathrm{wt} / \mathrm{v}$ gave a maximum absorbance raise in concentration above stated in literature will not have much effect on absorbance. Hence, $0.2 \%$ wt/v TO was chosen as the optimum concentration sufficient to produce measurable color intensity. Likewise the amount of TO $(\mathrm{mL})$ required to obtain effective complexation was studied by adding the above optimized TO $(0.2 \% \mathrm{wt} / \mathrm{v})$ and varying the quantity added (1-3 $\mathrm{mL})$ at fixed drug concentration (15 $\mu \mathrm{g} \mathrm{mL}-1)$ Fig. 3(b). From the results it was found that $2 \mathrm{~mL}$ of $0.2 \% \mathrm{wt} / \mathrm{v}$ TO is sufficient to make complex. Then the absorbance of the chromogen from the time of extraction (considered as $0 \mathrm{~min}$ ) to various time intervals were determined and the results were plotted against time vs. absorbance (Fig. 3(c)). The plot shows that the chromogen was stable more than $2 \mathrm{~h}$.

\section{Study of interference and placebo study}

The studied excipients do not cause any interference in the estimation of the drug (Table 4). Likewise the placebo mixture of above excipients was prepared without the drug and studied at the wavelength of estimation for to determining any absorbance for the chloroform extractable material present in the placebo mixture. Absence of orange red color in the extract revealed the selectivity of the present method for the analyte of interest.

Table 4: Study of interference of excipients

$\begin{array}{ll}\begin{array}{l}\text { Excipients used } \\ (\mathbf{1 0} \mathbf{~ m g})^{\mathbf{a}}\end{array} & \begin{array}{l}\text { \%Recovery }^{(\mathbf{S S D})^{\mathbf{b}}} \\ \hline \text { Magnesium stearate }\end{array} \\ \text { Starch } & 99.98 \pm 0.741 \\ \text { Talc } & 100.05 \pm 0.651 \\ & 100.07 \pm 0.445\end{array}$
${ }^{a}$ Quantity of excipients added per $100 \mathrm{mg}$ of $\mathrm{TL} ;$
${ }^{b}$ mean of 5 determinations

Table 2: Assay of TL by the proposed method

\begin{tabular}{|c|c|c|c|c|c|c|c|}
\hline \multirow[t]{2}{*}{ Sample } & \multirow{2}{*}{$\begin{array}{l}\text { Label claim } \\
\text { (mg/tab) }\end{array}$} & \multicolumn{2}{|c|}{ Amount (\%) ${ }^{a}$} & \multicolumn{2}{|c|}{$\%$ RSD $^{\mathrm{a}}$} & \multicolumn{2}{|c|}{ Confidence $^{\mathrm{b}}$} \\
\hline & & Proposed & Reported & Proposed & Reported & t-test & F-test \\
\hline I & 4 & 99.97 & 99.97 & 0.76 & 0.98 & 0.1687 & 1.276 \\
\hline
\end{tabular}

Table 3: Results of precision and accuracy of the method

\begin{tabular}{|c|c|c|c|c|c|c|c|}
\hline \multirow{3}{*}{$\begin{array}{l}\text { Conc. } \\
\left(\mu g \mathrm{~mL}^{-1}\right)\end{array}$} & \multicolumn{4}{|c|}{ Precision } & \multicolumn{3}{|c|}{ Accuracy } \\
\hline & \multicolumn{2}{|c|}{ Inter-day } & \multicolumn{2}{|c|}{ Intra-day } & \multirow[b]{2}{*}{$\begin{array}{c}\text { Spike } \\
\text { level (\%) }\end{array}$} & \multirow[b]{2}{*}{$\begin{array}{c}\% \\
\text { Recovery }^{a}\end{array}$} & \multirow[b]{2}{*}{$\%$ RSD $^{a}$} \\
\hline & $\begin{array}{l}\text { Amt found } \\
\left(\mu g \mathrm{~mL}^{-1}\right)^{a}\end{array}$ & $\%$ RSD $^{\mathrm{a}}$ & $\begin{array}{l}\text { Amt found } \\
\left.(\mu \mathrm{g} \mathrm{mL})^{-1}\right)^{a}\end{array}$ & $\%$ RSD $^{a}$ & & & \\
\hline \multirow[t]{3}{*}{15} & 14.95 & 0.958 & 14.95 & 0.995 & 75 & 100.00 & 0.98 \\
\hline & & & & & 100 & 99.96 & 0.92 \\
\hline & & & & & 125 & 99.94 & 1.02 \\
\hline
\end{tabular}




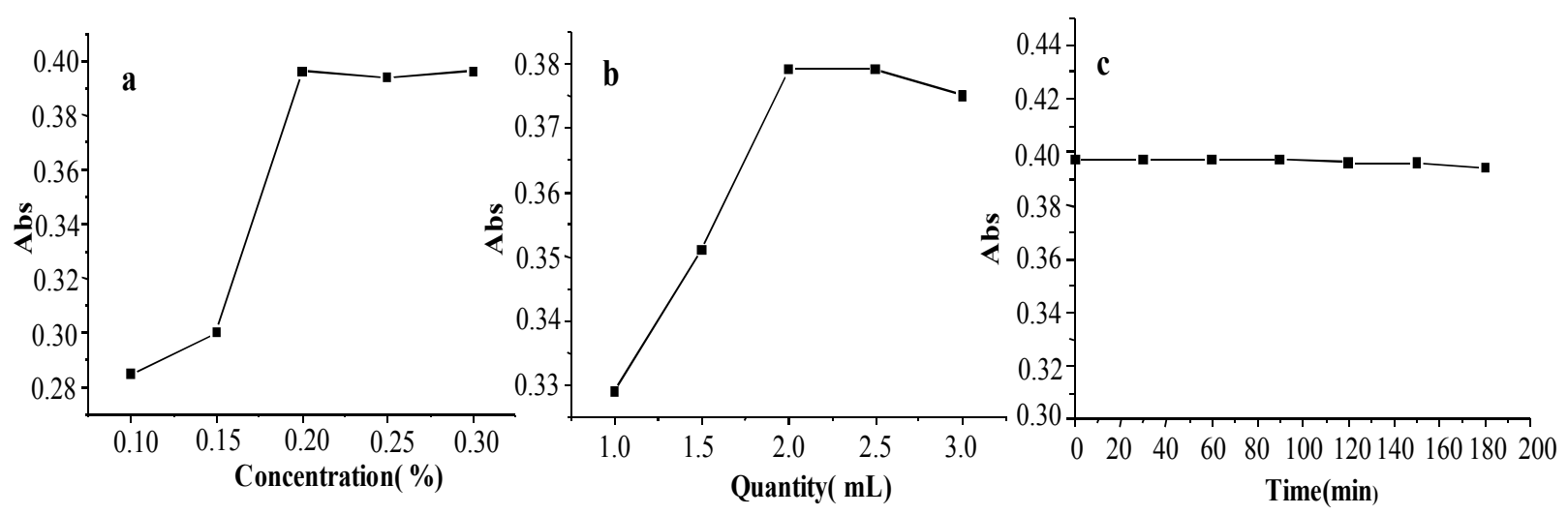

Figure 3: Effect of concentration (a) and quantity (b) of TO on absorbance ion pair as well as stability study on color of TL-TO ion pair (c)

Table 5: Robustness and ruggedness

\begin{tabular}{|c|c|c|c|c|}
\hline \multicolumn{5}{|c|}{ Robustness } \\
\hline Wav & ngth (nm) & \%RSD* & TO conc.(\%w/v) & $\%$ RSD* \\
\hline 502 & & 0.542 & 0.21 & 0.415 \\
\hline 504 & 0.713 & 0.19 & 0.845 & \\
\hline \multicolumn{5}{|c|}{ Ruggedness } \\
\hline & Analyst & \%RSD* & UV system & \%RSD* \\
\hline & $\mathrm{I}$ & 0.426 & I & 0.614 \\
\hline & II & 0.563 & II & 0.553 \\
\hline
\end{tabular}

${ }^{*}$ Mean of 5 determinations

\section{Robustness and ruggedness}

The results of robustness by changing the wavelength of estimation and change in TO concentration obtained were within the suggested limits for \% RSD (<2\%) given in the analytical method validation guidelines (Table 5). Ruggedness was established by determining TL in the tablet formulation using two different spectrophotometers and two different analysts (I and II). The results obtained are within the recommended \% RSD limit (<2\%).

\section{DISCUSSION}

The positively charged quaternary amine of the azo dye TO formed an ion-association complex with negatively charged TL. These oppositely charged TL and TO ions formed a single ion pair of TL-TO complex by electrostatic force of attraction.

The absorbance of the complex obeyed Beer's law over the range $1-30 \mu \mathrm{g} / \mathrm{mL}$ with a correlation coefficient of 0.9945 . Recovery and precision of the method are also comparable to those of previously reported methods for the drug [5-8].

\section{CONCLUSION}

The proposed ion-association extractive colorimetric estimation of tolterodine tartrate (TL) in bulk and in formulation using tropaeolin OOO-1 as chromogenic agent is sensitive, specific (selective), rapid and cost effective. Since the proposed method makes use of simple reagents in low concentrations the method should more cost-effective than other sophisticated methods. Thus, this method is suitable for routine determination of tolterodine tartrate in bulk and in its formulations.

\section{ACKNOWLEDGEMENT}

The authors acknowledge financial support via grants from Korea CCS R\&D Centre funded by Ministry of Education, Science and Technology of the Korean Government.

\section{REFERENCES}

1. Sweetman SC. The Complete Drug Reference, Pharmaceutical Press, London, 32nd edition, 1999.

2. Martindale. The Extra Pharmacopeia, Pharmaceutical Press, Great Britain: 30th edition, 1993.

3. Ulahannan $D$, Wagg $A$. The safety and efficacy of tolterodine extended release in the treatment of 
overactive bladder in the elderly. Clini Interven Aging. 2009; 4:191-196.

4. Gillberg PG, Stahl M, Sparf B, Nilvebrant L, Andersson KE. Tolterodine-a new bladder-antimuscarinic agent, Euro J Pharmacol. 1997; 327: 195-207.

5. Shetty SK, Shah A. New Spectrophotometric method for estimation of tolterodine in bulk and pharmaceutical formulation. Inter J Pharma Sci Res. 2011; 2: 14561458.

6. Nanda RK. Gaikwad J, Prakash A. Simultaneous spectrophotometric estimation of tamsulosin and tolterodine in its pharmaceutical dosage form. J Pharm Res. 2009; 2: 1266-1268.

7. Nanda RK, Gaikwad J, Prakash A. Estimation of tamsulosin and tolterodine in its Pharmaceutical dosage form by Spectrophotometric method. Inter J Pharm Tech Res. 2009; 1: 420-423.

8. Nanda RK, Gaikwad J, Prakash A. Simultaneous spectrophotometric estimation of tolterodine in pharmaceutical dosage form. Res J Pharm Tech. 2009; 2; 312-314.

9. Vanilatha $S$, Theresa MM, Rasanna NP, Shanthakumari $D$, Harika B, Sirisha $P$, Xavier MA, Balakumari KG. New method development and validation of tolterodine using visible spectrophotometry. Int $\mathrm{J}$ Science Innov Discov 2011; 1: 288-293.

10. Yadav M, Upadhyay V, Chauhan V, Solanki G, Jani A, Baxi GA, Singhal $P$, Shrivastav PS, LC-MS-MS Separation and simultaneous determination of tolterodine and its active metabolite, 5-Hydroxymethyl tolterodine in human plasma. Chromatographia. 2010: 72: 255-264.

11. Macek J, Ptacek P, Klima J. Determination of tolterodine and its 5-hydroxymethyl metabolite in human plasma by hydrophilic interaction liquid chromatographytandem mass spectrometry. J Chromatogra, 2009: 877: 968-974.
12. Xia ZL, Chen ZY, Yao TW. An enantiospecific HPLC method for the determination of (S) -enantiomer impurities in (R)-tolterodine tartarate. Pharmazie. 2007; 62: 170 - 173.

13. Swart R, Koivisto $P$, Markides EK. Capillary solid-phase extraction-tandem mass spectrometry for fast quantification of free concentrations of tolterodine and two metabolites in ultra filtered plasma samples. $J$ Chromatogr B. 1999; 736: 247-253.

14. Yanamandra R, Vadla CS, Puppala U, Patro B, Murthy $Y L N$, Ramaiah PA. A new rapid and sensitive stability-indicating UPLC assay method for tolterodine tartrate: Application in pharmaceuticals, human plasma and urine Samples. Scientica Pharmaceutica. 2012; 80: 101-114.

15. Sakra MM, Nashara RM. Potentiometric determination of tolterodine in batch and flow injection conditions. Talanta. 2012; 96: 153-160.

16. Usharani BG, Chandrasekhar B, Devanna N. Extractive colorimetric method development and validation for erlotinib in bulk and tablet dosage form. J Appl Pharmaceut Sci. 2011; 1: 176-179.

17. Parameswararao K, Satynarayana MV, Raju TN, Ramana GV. Sensitive extraction spectrophotometric methods for the determination of atazanavir sulfate in bulk and in pharmaceutical formulations. Rasayan $\mathrm{J}$ Chem, 2012; 5: 481-485.

18. Ganesh M, Thangabalan B, Patil R, Ganguly S, Sivakumar $T$. Simple extractive colorimetric determination of oxaprozin by acid-dye complexation methods in solid dosage form. E-J Chem, 2008; 5: 593-597.

19. The United States Pharmacopeia. The National Formulary 19, US Pharmacopeial Convention Inc., Rockville, MD 2000.

20. ICH. Validation of analytical procedures: Text and methodology Q2 (R1), International Conference on Harmonization, Geneva, November 1996. 